\title{
Thaksin Shinawatra y el sistema político tailandés, 2001-2006
}

DOI: 10.32870/mycp.v3i9.471

\section{Resumen}

La irrupción de Thaksin Shinawatra en el máximo escenario político nacional, al triunfar en las elecciones generales de enero de 2001, representó un verdadero hito en la historia política contemporánea de Tailandia, no sólo porque ejemplifica una combinación exitosa entre negocios y política, tan propia de Tailandia, sino sobre todo porque, por la vía de la institucionalidad y cronograma democrático, impulsó una "Agenda Nacional" que, por un lado, generó amplias expectativas y apoyo de parte de los sectores populares, tanto rurales como urbanos, pero por otro, despertó suspicacias y francamente desconfianza por parte de la clase política tailandesa tradicional sobre su liderazgo y peculiar estilo de gobernar que, muy pronto, empezaron a tildar de populista.

En efecto, con la idea de superar los estragos de la crisis asiática de 1997, detonada precisamente en Tailandia, y posicionar y promover a Tailandia como potencia regional y activo protagonista en el escenario económico global, Thaksin convocó a un "nuevo pacto social" en donde el Estado-asistencialista y benefactor debía desempeñar un rol central, tanto para garantizar la viabilidad de un paquete de reformas sociopolíticas encaminadas a su propia modernización, tanto como para propiciar la realización de negocios empresariales,

Artículo recibido el 10 de diciembre de 2013 y dictaminado el 13 de enero de 2014.

1. UAM-Iztapalapa. Correo electrónico: daglo@unam.mx 
toda vez que "política y negocios son inseparables". En este contexto y apoyado en una estable y cómoda mayoría parlamentaria, Thaksin Shinawatra acometió reformas conducentes a la construcción de un "nuevo orden social" para favorecer a los sectores sociales tradicionalmente afectados por las crisis, particularmente los pequeños y medianos negocios urbanos, así como las grandes empresas rurales; implantó la nueva economía o "Thaksinomía”, reformó el servicio civil, modernizó la antigua burocracia, emprendió "campañas de limpieza nacional", libró "guerras" contra el narcotráfico y la corrupción, etc., pero también fue evidente que usó y manejó el país como un negocio personal y familiar; fue renuente e intolerante a las críticas, particularmente con aquellos que lo acusaban de autoritario y de ejercer un "populismo irresponsable". Por este camino fracturó y polarizó la sociedad tailandesa.

En definitiva, aunque Thaksin Shinawatra ha sido el único político tailandés que ha ganado cuatro elecciones generales consecutivas y por amplio margen, ha sido también el único primer ministro que ha permanecido en su cargo más de cinco años, completando un "periodo constitucional de cuatro años", que nadie había logrado, fue derrocado por un golpe de Estado el 19 de septiembre de 2006, que lo condenó al exilio e interrumpió el proceso democrático que duraba más de 15 años, algo inédito en la historia política de Tailandia.

Palabras clave: populismo, reforma del Estado, Thaksinomía, dictadura parlamentaria, golpe de Estado.

\section{Abstract}

The irruption of Thaksin Shinawatra on the maximum national political stage, to succeed in the general election of January 2001, represented a true milestone in the political history of contemporary Thailand, not only because it exemplifies a combination successful among business and political, so characteristic of Thailand, but above all because, by way of the institutionality and democratic schedule, he promoted a "National Agenda" that on the one hand, it generated expectations and support on the part of the popular, both rural and urban sectors, but on the other hand, aroused suspicions and frankly distrust by the traditional Thai political class about his leadership and unique style of governing that, very soon, they began to tick of populist.

Indeed, with the idea of overcoming the ravages of the Asian crisis of 1997, detonated precisely in Thailand, and position and promote Thailand 
as a regional power and active protagonist on the global economic stage, Thaksin called for a "new social pact" where the welfare State and welfare should play a central role, had a central role, both for ensuring the viability of a socio-political reforms aimed at its own modernization package so as to promote the realization of enterprise business, cough after that "politics and business are inseparable". In this context and rested on a stable and comfortable parliamentary majority, Thaksin Shinawatra rushed reforms conducive to the construction of a "new social order" to favour the social sectors traditionally affected by crises, particularly small and medium-sized urban businesses as well as large rural enterprises; he introduced the new economy or Thaksinomia, reformed the civil service, he modernized the old bureaucracy, undertook "national clean up campaigns", fought "wars" against drug trafficking and corruption, etc., but it was also evident that he used and managed the country as a personal and family business; he was reluctant and intolerant to criticism, particularly with those who accused him of authoritarian and exert an "irresponsible populism". By this way, it fractured and polarized Thai society.

In short, although Thaksin Shinawatra has been the only Thai politician who has won four consecutive and by a wide margin general elections; he has also been the only Prime Minister who has been in office more than five years, completing a "constitutional four-year period," which no one had achieved, was overthrown by a coup on 19 September 2006, which condemned him to exile and interrupted the democratic process that lasted more than 15 years, something unprecedented in Thailand's political history.

Keywords: populism, State reform, Thaksinomia, parliamentary dictatorship, coup d'etat.

\section{Preámbulo}

El presente trabajo es parte de un proyecto mayor referido al papel del llamado "Clan Shinawatra" en la política tailandesa, entre los años 2001 y 2013. En este lapso la familia Shinawatra liderada por el hermano mayor Thaksin, ha conquistado el máximo poder político en Tailandia por la vía de la democracia electoral en 2001, lo ha perdido por la vía de un golpe de Estado militar en 2006 y lo ha reconquistado, de nueva cuenta, por el camino de la democracia electoral en 2011, reteniéndolo hasta el día de hoy (2013). En este sentido, tanto de manera directa como indirecta, el "Clan Shinawatra" ha sido uno de 
los grandes y definitivos protagonistas del escenario histórico y político de la Tailandia de principios del siglo XxI, proceso general que se aborda a través de tres ensayos históricos, secuenciados cronológicamente: el primero, que aquí presentamos, se refiere a la irrupción, conquista del poder, consolidación política, derrocamiento y exilio del líder fundador y motor del proyecto político: Thaksin Shinawatra, proceso que se desarrolló entre 2001 y 2006. En el segundo trabajo, en proceso, delimitado entre 2006 y 2011, se dará cuenta de las crecientes pugnas y luchas políticas entre las fuerzas pro y anti-Thaksin, desencadenadas a partir del golpe de Estado, que han sumido a Tailandia en una profunda y prolongada crisis política y social, cuya espiral de violencia culminó dramáticamente en Bangkok a mediados de mayo de 2010, por lo que le hemos denominado la "Batalla por Tailandia".

Finalmente, el tercer ensayo histórico, también en proceso de desarrollo, que hemos denominado "El regreso del Clan Shinawatra", aborda el periodo marcado por el triunfo electoral de Yingluck Shinawatra, la hermana menor del clan, en julio de 2011, y culmina en diciembre de 2013, momentos en que la nueva primera ministro ha cumplido un poco más de dos años de gestión, cuyo liderazgo político en proceso de consolidación se debate entre la pesada sombra del caudillismo de su hermano mayor Thaksin y la compleja tarea de lograr la reconciliación nacional, la recuperación de la estabilidad y gobernabilidad, condiciones fundamentales para la viabilidad de la Tailandia del siglo XXI y que no siempre, tratándose de dicho país, estarán aseguradas.

\section{La irrupción política de Thaksin Shinawatra}

La llegada de Thaksin Shinawatra a la arena política tailandesa se hizo por la puerta grande de los negocios y sus conexiones, lo cual no es ninguna novedad en Tailandia. No hay dudas al respecto: se trata de un megaempresario de las telecomunicaciones que, en menos de un quinquenio, ha hecho una fortuna superior a los 2,000 millones de dólares, partiendo prácticamente de la nada. Pero no sólo se trata de un magnate para la escala tailandesa, se trata de un empresario exitoso en un campo industrial de vanguardia y de máxima competitividad a nivel global, como lo son las telecomunicaciones. Un campo que ubica a Tailandia en el umbral de la modernidad y la globalización.

Lo que sí representó una mayor novedad fue la estrategia y el protagonismo político-empresarial de Thaksin, que muy pronto empezara a ser motejado como el Berlusconi tailandés. Al respecto, en el transcurso de la primera 
semana de diciembre de 2000 , en plena recta final de la campaña electoral para las elecciones generales de enero de 2001, apareció en la mayoría de los periódicos de Tailandia una inserción que, entre rasgos autobiográficos y propuestas programáticas, retrataba de cuerpo entero la idiosincrasia de Thaksin y el nuevo tipo de liderazgo que propone. En primer lugar estaba su categórico compromiso con el país y con "su gente":

Estimados hermanas y hermanos tailandeses: la nación tiene, aún, muchos y variados problemas que requieren de una rápida solución. En estos momentos, yo creo firmemente que ustedes me deben confiar a mí y a mi partido, el Tahi Rak Tahi [los tailandeses aman a los tailandeses], tomar la responsabilidad para resolver el sufrimiento de la gente y construir el futuro de la nación (Phongpaichit y Baker, 2009: 84).

En segundo lugar, sobre la base de su origen y esfuerzo, garantizaba el cumplimiento de su compromiso político-social:

La llegada de Thaksin

Shinawatra a la arena política tailandesa se hizo por la puerta grande de los negocios y sus conexiones, lo cual no es ninguna novedad en Tailandia. No hay dudas al respecto: se trata de un megaempresario de las telecomunicaciones que, en menos de un quinquenio, ha hecho una fortuna superior a los 2,000 millones de dólares, partiendo prácticamente de la nada. Pero no sólo se trata de un magnate para la escala tailandesa, se trata de un empresario exitoso en un campo industrial de vanguardia y de máxima competitividad a nivel global, como lo son las telecomunicaciones

Hermanas y hermanos: yo vengo del campo. Hice mis estudios de primaria en una escuela pública en Sankamphaeng. Fui aceptado en la Academia policial gracias a un examen de admisión y gané una beca del gobierno para obtener mi doctorado en Estados Unidos de Norteamérica. Como chiquillo campesino, hijo del propietario de una cafetería, ayudé a mi padre con sus huertos, repartiendo periódicos y operando cines móviles, hasta que empecé el negocio de la computación. Me casé con la hija de un oficial de 
policía, quien había crecido en un hostal policial. Nosotros partimos juntos desde cero, enfrentando problemas y disfrutando triunfos, ayudándonos mutuamente para sacar adelante nuestros tres niños, desde su nacimiento hasta lo que son hoy, en su plena juventud.

Por mis propios esfuerzos, partí dirigiendo una empresa con siete personas, hoy en día son más de seis mil empleados, que se multiplican en millones de empleos parciales indirectos. He colocado satélites comunicacionales en el espacio. He invertido en el extranjero. Antes yo tenía que andar a la caza de mis clientes para que me pagaran sus cuentas. Llegué a ser un mal deudor de los bancos, conocido como un deudor incumplido, incluso casi fui a la bancarrota en tres ocasiones pero, actualmente, tengo más riqueza y prosperidad como nunca antes imaginé. Aun así, mis amigos de hoy van desde aquellos que rentan motocicletas para trabajar, hasta presidentes de grandes países.

Hoy día tengo 51 años de edad. La experiencia y el conocimiento que he adquirido a lo largo de mi vida, no es algo que yo quiera guardar sólo para mí. Déjenme consagrar el resto de mi vida a este país que me ha dado mucho más de lo que yo merecía haber recibido. Deseo combinar mi conocimiento con la moderna tecnología para resolver los problemas nacionales (Phongpaichit y Baker, 2009: 85).

Reivindicando su origen social promisorio, testimoniado su carácter de emprendedor a través de una ruta empresarial exitosa y garantizada la viabilidad de su proyecto nacional, con base en su experiencia, conocimiento y nacionalismo a toda prueba, la proclama política de Thaksin culmina su oferta programática centrándose en el que será su principal cliente electoral: el pueblo, en su dimensión rural y urbana:

Hermanas y hermanos: como alguien nacido en el campo, me gustaría que los agricultores tuvieran una vida en la que pudieran ser autosuficientes, sin deudas, y con suficiente dinero para educar a sus hijos. Asimismo, me gustaría conseguir un seguro de protección para ellos cuando estuvieran enfermos y vendieran sus productos a un menor precio por la explotación comercial de que son objeto y además garantizar que tuvieran trabajo complementario en periodos de desempleo estacional.

Como tailandés me gustaría ver que mi país tuviera una moderna burocracia que sirva a la gente y les proporcione datos e información estratégica para sus negocios, más que fiscalizarlos y controlarlos excesivamente. Me gustaría ver una rápida reducción de la corrupción a través de un buen sistema de prevención de esas prácticas, así como un muy buen y digno sistema de previsión y bienestar social, con funcionarios públicos idóneos. De la misma manera, me gustan los 
políticos que aman a sus conciudadanos, son compasivos y generosos, y no egoístas que sólo ven por sus carreras políticas e intereses personales, olvidando la importancia fundamental del pueblo y la nación toda (Phongpaichit y Baker, 2009: 87).

Hasta aquí, y sobre la base de su propia proclama, hemos contextualizado y adelantado algunos de los contenidos centrales de su proyecto políticoprogramático. A continuación, con una mayor profundidad y concisión, desarrollaremos los alcances e implicaciones de dicha propuesta, empezando por algunas precisiones fácticas en la carrera política de Thaksin Shinawatra. A saber, el primer paso importante que dio Thaksin para cruzar la delgada línea entre negocios y política se dio en noviembre de 1994, cuando se unió al gabinete de Chuan Leekpai, en tanto ministro de Asuntos Exteriores, como parte de la cuota ministerial que le correspondía al partido Phalang Tham (Fuerza Moral), miembro de la coalición gobernante, liderado por Chamlon Srimvang, antiguo ex militar, convertido en un lego budista, ascético, de gran prestigio, quien a su vez invitó a Thaksin y a otros miembros de la nueva generación de hombres de negocios de Bangkok, a unirse al Phalang Tham. Estos "nuevos ricos" se sintieron atraídos por las campañas antimilitaristas y anticorrupción burocráticas emprendidas por dicho partido y su líder moral.

Una segunda incursión política de importancia se produjo con su participación como candidato al Distrito Electoral Central de Bangkok, en las elecciones de julio de 1995, en donde obtuvo un holgado triunfo por sobre el Partido Demócrata, el partido gobernante y más popular de Tailandia en ese momento. No obstante, se abstuvo de participar en el proceso de reelección, en noviembre de 1996, porque "la atmósfera política dentro del Phalang Tahm no era buena", según sus propias percepciones. Sin embargo, la verdad era otra, aunque no tan diferente: por primera vez su imperio empresarial, comercial y financiero, construido con base en concesiones otorgadas por sus conexiones políticas, estaba ya bajo serias amenazas de fiscalización y control por parte de las nuevas regulaciones estatales respecto de la tradicional y siempre controvertida relación entre política y negocios en Tailandia. Pero, para suerte de Thaksin, que no para Tailandia, ocurrió el estallido de la más severa crisis económica sufrida por el país en su historia reciente, la crisis económica de 1997, detonada precisamente en Tailandia y propagada desde allí a la región del sureste asiático, y al mundo. Curiosamente, dicha crisis más bien favoreció que perjudicó a Thaksin, no sólo porque interrumpió el proceso de regulación y 
fiscalización de que era objeto, sino también porque le propició las condiciones internas para potenciar su proyecto y discurso político, en tanto "salvador" de la crisis, tal como se verá más adelante.

En efecto, una vez situado en los terrenos de la acción y gestión política, e inspirado en su lógica empresarial, se avocará de inmediato a la organización del instrumento político acorde con sus intereses: la fundación del partido Thai Rak Thai (TRT), cuyo significado es: los tailandeses aman a los tailandeses, que se constituirá en la plataforma política electoral, desde la cual Thaksin luchará por la supremacía del poder político en Tailandia. Al respecto, si consideramos que la fundación del TRT fue el 14 de julio de 1998 y en las elecciones generales del 6 de enero de 2001 obtuvo una contundente mayoría nacional de $48 \%$ frente a $31 \%$ de su inmediato seguidor, el Partido Demócrata, ${ }^{2}$ lo cual habilitó para la formación de una sólida coalición política que, a su vez, facilitó a Thaksin Shinawatra la conquista de la máxima magistratura política del país, cual es la oficina del primer ministro (PM), asumida el 9 de febrero de 2001; entonces estamos también, que duda cabe, frente a un éxito político-electoral indiscutible, aunque no menos controvertido, como se verá más tarde. En suma, la incursión de Thaksin en la política tailandesa ha sido tan meteórica como la construcción de su propia fortuna personal, con la que aterrizó en la arena política.

Anunciada primero como "Agenda Nacional" del TRT y constituida luego en el programa básico de su gobierno, dicha agenda perfila desde el inicio la naturaleza y prioridades del régimen de Taksin, cuyos 11 puntos se transformarán en 11 grandes ejes de acción política dirigida básicamente a los sectores urbanos y rurales de Tailandia. A saber:

1. Desarrollar tanto el mercado de capitales como el sector financiero.

2. Reestructurar la economía y las deudas nacionales.

3. Generar ingresos y resolver el problema del desempleo, particularmente en el ámbito urbano.

4. Revivir a los agricultores tailandeses.

5. Educación: formar gente para construir una nación fuerte y solidaria.

6. Erradicar el consumo de drogas de la sociedad tailandesa.

7. Declarar la guerra a la corrupción.

8. Transformar a la salud pública para asegurar la atención popular.

2. Véase cuadro 3.3 en Phongpaichit y Baker, 2009: 89. 
9. Formar familias fuertes y aumentar el papel político de la mujer.

10. Privatizar las empresas estatales.

11. Persistir en la construcción de una nueva política y un nuevo papel regional para Tailandia.

Si desde su formulación la "Agenda Nacional" de Thaksin despertó suspicacia en la clase política tailandesa, su aplicación a través de un gran paquete de reformas del Estado no dejó dudas para sus detractores: se trataba de un programa con una alta dosis de populismo.

Catapultado por esta plataforma programática y electoral, la inercia política exitosa de Thaksin no se detuvo. Por lo pronto, ha sido el político que ha ganado cuatro elecciones generales consecutivas y por amplio margen, más que ningún otro líder en la historia democrática de Tailandia. Ha sido también el único primer ministro que ha permanecido más de cinco años en el cargo. Obviamente, el único PM que ha logrado completar el periodo constitucional de cuatro años, establecido para dicho encargo. La imagen exitosa es, como se ha dicho, indiscutible, pero también ha crecido la imagen controvertida: Thaksin, muy fiel a la tradición tailandesa, ha usado el dinero para ganar el poder y luego utilizar el poder para hacer dinero, bajo la lógica de que:

Política y negocios son inseparables. Nosotros tenemos que aceptar esa realidad. La política es como el Sol, los negocios como la Tierra. Si están muy cerca hace demasiado calor, si están muy lejos demasiado frío. Deben estar equidistantes para ser productivos. Por eso, ellos son inseparables (Phongpaichit y Baker, 2009: 41).

Ahora bien, ¿cómo explicamos la vertiginosa carrera política de Thaksin Shinawatra que lo ha llevado, en brevísimo tiempo, al cargo político más importante del Gobierno tailandés? Al respecto, si bien es cierto que en la historia, y mucho menos en la política, no hay hechos y/o procesos histórico-sociales que se expliquen unicausalmente, la estrategia de Thaksin de haber utilizado la crisis asiática de 1997, detonada precisamente en Tailandia, como el tema central que catapultó su campaña y nutrió su programa de gobierno, fue un acierto. En efecto, dicha estrategia general, que se desplegó en varios frentes tácticos, empezó como ya se ha dicho, con la creación del partido político instrumental, el TRT, que desde sus propias bases fundacionales privilegia la superación de la crisis como su primera prioridad política; continúa con 
el desplazamiento del Partido Demócrata (PD) y de su líder Chuan Leekpai, partido y líder tremendamente exitoso en la década de los noventa (Toledo, 2012: 37-40), pero que en los albores del siglo XXI han sido incapaces para revertir los efectos de la crisis, con el consiguiente debilitamiento de su opción político-electoral, creando un vacío de poder y liderazgo que Thaksin aprovechó, oportuna y hábilmente.

A partir de allí, anclado y proyectado por la amplia plataforma políticoelectoral que ex profeso le brinda el TRT, proclamó su oferta programática: dar una mejor y más oportuna respuesta económica, social y política a la crisis de 1997 que, no sólo ha inhibido el crecimiento económico y provocado la caída de los precios, sino que ha aumentado el desempleo, detonado la inseguridad social e incrementado la marginación de amplios sectores urbanos y rurales, tradicionalmente excluidos de los beneficios del "éxito económico" del pasado reciente. El llamado "Quinto tigre asiático" está postrado, hay que levantarlo (Toledo, 2012: 19-22).

\section{Hacia la construcción de un nuevo pacto social para Tailandia}

El contundente triunfo electoral, y la sólida coalición política que se organizó, permitieron una estable y cómoda mayoría parlamentaria que no sólo garantizó la estabilidad política del gobierno de Thaksin, despejando los temores de los inversionistas, sino que también hizo creíble su proyecto económico de retomar el camino del crecimiento y reorientar el modelo asiático de desarrollo, aprovechando las ventajas competitivas de la propia Tailandia. En la construcción de esta "nueva economía", o "Thaksinomía" como se le empieza a denominar, no sólo se debe tomar distancia del modelo neoliberal que trata de imponer el FMI, sino que hay que decidirse por un papel más positivo y activo del Estado en la protección y desarrollo de empresas y sectores nacionales, que permitan superar las desventajas contra las economías más avanzadas, tal como lo parafraseó el propio Thaksin: "Si yo deseo jugar golf con Tiger Woods, Tiger debe darme suficiente ventaja" (Phongpaichit y Baker, 2009: 100). En otras palabras, para lograr la meta del crecimiento económico, el Gobierno tailandés debe desarrollar un rol más activo que antes en la protección y promoción de la economía doméstica, sin olvidar sus implicaciones regionales y globales, tal como en su tiempo lo hicieron Japón, Corea del Sur y Taiwán.

Ansioso por ser reconocido como un moderno y dinámico hombre de negocios empeñado en cambiar la cara del escenario político tailandés, Thaksin 
Shinawatra quiso imprimir ese carácter a su equipo de gobierno, caracterizado como la conformación de un nuevo tipo de gestores empresariales, modernos, emprendedores, arriesgados, pragmáticos y nacionalistas, perfectamente conscientes de la coyuntura nacional e internacional por la que atraviesa la economía tailandesa, pero también perfectamente conscientes de que las crisis son al mismo tiempo momentos de oportunidades, no sólo para la recuperación económica, sino también para la política y los negocios, acertadamente reseñada por Thaksin en el siguiente colofón:

Una empresa es un país. Un país es una empresa. Son lo mismo. La gestión es la misma. Es el gobierno administrado por la economía política. De ahora en adelante, estamos en la era de la administración por la economía política y no por cualquier otro medio. La economía política es el factor determinante (Phongpaichit y Baker, 2009: 101).

Si ya hemos visto que Thaksin es un entusiasta partidario de la intervención del Estado en la economía, lo es también en el ámbito de lo social. Firme promotor de la idea del Estado asistencialista y benefactor, no sólo como la herramienta básica para resolver el problema de la pobreza, lograr una distribución de la riqueza más justa y acceder a una justicia social más extendida, sino también propugnar por la organización de un sistema político-social más orgánico, transparente, estable y funcional, que facilite la participación y militancia política, particularmente de las masas urbanas y rurales, a quienes el Gobierno ha identificado como su clientela política más importante. En efecto, entre los sectores sociales tradicionalmente afectados por las crisis, especialmente el amplio sector de los pequeños y medianos negocios urbanos, así como las grandes masas rurales, encontrarán Thaksin y el TRT su capital político-electoral. Como quedó en evidencia en la mencionada "Agenda $\mathrm{Na-}$ cional", la focalización de la oferta política en estos sectores sociales no es por cierto casual, todo lo contrario, es totalmente deliberado: se trata de amplios conglomerados sociales a escala nacional que, como se ha dicho, son los más golpeados por la crisis y han permanecido prácticamente excluidos de los beneficios del desarrollo económico, por lo tanto, los que más necesitan de la asistencia y apoyo del Estado en la promoción de sus negocios y cultivos. Por cierto, no está demás recordar que representan también, y a nivel nacional, un enorme potencial electoral. 
Si en lo económico se priorizó la superación de la crisis por la vía de la recuperación del crecimiento del PNB, en lo político-social se pronunció por una reforma del Estado que garantizara un "nuevo orden social", que empieza por una transformación del servicio civil y de la antigua burocracia y culmina con una "campaña de limpieza nacional" tendente a extirpar una serie de lacras sociales que no sólo obstruyen el desarrollo integral, sino que aquejan la vida social tailandesa y afectan su imagen exterior. Tarea no menor que la primera, particularmente la reforma burocrática. Basta recordar que, desde la implantación misma del gobierno constitucional en 1932 hasta 1992, fecha marcada como el inicio de los llamados gobiernos civiles, democráticamente electos, el poder acumulado por la burocracia frente a la clase política, la sociedad civil y, aun los militares, ha sido enorme e incontrarrestable: a principios del siglo XXI representan unos dos millones de funcionarios, distribuidos a lo largo y ancho del país, que consumen $80 \%$ del presupuesto gubernamental. En suma, y respecto a la antigua burocracia, el juicio de Thaksin es contundente:

La burocracia tailandesa ha sido demasiado poderosa, demasiado torpe y demasiado ignorante de la dinámica actual de los negocios en el mundo. Han perdido no sólo su razón de ser, sino también la capacidad para ayudar a Tailandia a desarrollarse y progresar. Como resultado de esta actividad, Tailandia permanece atrasada respecto a muchos otros países. Muchos políticos, tanto como burócratas, simplemente no son modernos. Ellos han fracasado para mantener el orden público en un mundo cambiante y globalizado. La crisis de 1997 ha sido el resultado de esta simple y total incapacidad para comprender el mundo actual (Phongpaichit y Baker, 2009: 172).

Los proyectos y discusiones para reformar y modernizar la burocracia no empezaron con Thaksin, han sido constantes por lo menos desde las últimas dos décadas del siglo pasado, pero han resultado ineficaces. Es más, en los círculos político-sociales, y aun académicos, se ha llegado a una suerte de convicción de que, dado el tamaño de dicha empresa, sólo podría ser acometida con éxito si la realizara el propio rey de Tailandia, Bhumibol Adulyadej. Nadie más, ni persona ni entidad alguna. Pero, he aquí que el ascenso al poder del nuevo primer ministro Thaksin Shinawatra, dotado de una indiscutible mayoría parlamentaria, no sólo representa para sus opositores una amenaza real para el statu quo burocrático, sino también y según esta misma óptica podría llegar a rivalizar con la capacidad transformadora del servicio civil del propio rey. En este sentido, es tan apabullante la mayoría parlamentaria 
de la que dispone el PM, que su ejercicio desde muy temprano empieza a ser calificado como "dictadura parlamentaria" o "dictadura democrática", con sus consiguientes detractores que reclaman por el ejercicio de un poder que ellos estiman como omnímodo.

Regresando a la tarea de la reforma del Estado, garante a su vez de la construcción del nuevo orden social que, según las expectativas del flamante primer ministro, debería empezar en Tailandia justo con el inicio del nuevo siglo, quedan al menos dos empresas generales que acometer: una, la inaplazable transformación de la estructura político-administrativa del país y, la otra, la también impostergable y no menos provocadora acción de la limpieza social. En ambos casos el lema inspirador debería ser, según el propio Thaksin, "Pensamiento nuevo, trabajo nuevo" (Ibarra, 2002: 258-260).

En cuanto a la primera tarea se trata, ni más ni menos, que de la creación y/o transformación de nuevos ministerios y departamentos, lo que implicará no sólo transferencias y movilización de personas, sino también reasignaciones presupuestales regionales; implica también la unificación y control de las metas de trabajo en áreas tan importantes como la economía y la seguridad, tanto en su dimensión interna como en el ámbito internacional. En esa misma dirección, es también imperativo el cambio en las condiciones del trabajo y en la determinación de los salarios, los cuales — según la impronta thaksinianadeberán ser determinados por el mercado y no por antiguos privilegios, como ha venido sucediendo. Naturalmente que medidas como éstas pasan a herir intereses y bienes, tanto de personas como de grupos, con el consiguiente aumento de detractores.

Respecto a la segunda acción programática, y como ya se ha adelantado en el presente trabajo, era indudable que la edificación del nuevo orden social requería de la remoción de obstáculos socioculturales profundamente arraigados en la sociedad tailandesa, como la corrupción y sus múltiples fórmulas; el narcotráfico, en su dimensión nacional como internacional; pero sobre todo la prevalencia de aquella imagen nefasta de Tailandia como el paraíso del placer y sus múltiples expresiones, particularmente la prostitución, trata de personas, explotación de seres humanos y pérdida de valores. En definitiva, se trataba prácticamente de una declaración de guerra en contra de las llamadas fuerzas oscuras, que no sólo obstruyen el funcionamiento de la democracia, sino que retardan el proceso de las reformas sociales.

Si bien el combate contra las denominadas lacras sociales, bajo el provocador principio-objetivo de limpieza social dio inicialmente algunos buenos 
resultados, generó también un cúmulo de problemas y un incremento en el número de detractores de dichas acciones, sobre todo cuando las tareas de "limpieza" quedaron bajo la tuición de grupos selectos de la policía y de los militares, tanto en el combate a la corrupción y el narcotráfico, como en el caso del trato a la "disidencia" en las provincias del sur del país, respectivamente.

Hasta aquí es más que notoria la preocupación política — para algunos, obsesión- de Thaksin Shinawatra de ser reconocido como un gran reformador social en su país, pero también lo es, en igual medida, su anhelo de reconocimiento como líder regional, terreno en el que sus acciones también han sido motivo de controversias. Por lo pronto, y bajo este imperativo de la notoriedad, el primer ministro aprovechará escenarios y circunstancias propicias para desplegar su histrionismo y proactividad en aras de la consolidación de dicho liderazgo regional en pro, eso sí, de una causa absolutamente legítima y plenamente asumida: el reposicionamiento de Tailandia en el escenario regional y mundial, su mejor carta, lo cual expresa claramente tanto en términos de estrategia general como de ventajas comparativas. Respecto de la primera, señala que:

Hoy día el mundo está profundamente interconectado. Nosotros sólo somos una parte de él. No podemos cerrar el país y ser autónomos, sin hacer nada, ni relacionarnos con nadie, viviendo sólo de la pesca y cosechando arroz. ¡ $\mathrm{Ni}$ pensarlo! Para tener edificios de concreto; es más, para tener cualquier cosa, tenemos que desarrollarnos a través de la interconexión con el mundo exterior.

Respecto de las ventajas comparativas, que son muy amplias, privilegia el rubro de las inversiones, sobre todo externas, y su gran potencialidad:

Invirtiendo en Tailandia, usted efectivamente está optando por múltiples trozos de una misma manzana: usted puede producir para 62 millones de personas en Tailandia y, al mismo tiempo, tener un mercado de 500 millones de gentes de la ASEAN [...] y en el corto plazo usted también puede aumentar su producción para 1,300 millones de chinos (Phongpaichit y Baker, 2009: 121).

No es exagerado decir que pocos primeros ministros, quizás ninguno si nos remitimos a la llamada era democrática tailandesa, han sido tan activos y estructurados en materia de política exterior. Los testimonios arriba citados dan cuenta de este rol y su evolución: a finales de los noventas, tanto empresarios, inversionistas, como analistas internacionales, veían a un Thaksin Shinawa- 
tra inseguro, hasta nervioso, defensor de una economía nacional protegida, empecinado en sacar a Tailandia de la crisis económica. Cinco años después lo reconocen ya como un líder regional activo, incluso agresivo, con vocación globalizadora, que no sólo ha sacado al país de la crisis sino que ha convertido al mercado tailandés en un lugar seguro y atractivo para traer y hacer dinero, además de que en la arena internacional de los negocios en telecomunicaciones, Thaksin Shinawatra se ha convertido ya en una trademark reconocida.

En efecto, en los foros y diálogos en el marco de la ASEAN, la figura política de Thaksin ha ido creciendo regionalmente, al punto de que en la IX Cumbre de dicha Asociación de 2003, junto a Singapur, encabezó el proyecto para convertir a la ASEAN en una suerte de Comunidad Económica Europea, con la idea de reforzar y modernizar los vínculos regionales para lograr una mejor interacción global. Así, aunque también han aflorado las divergencias regionales con Myanmar, Camboya y Malasia, mismas que han debilitado el protagonismo de Thaksin en esta materia, el primer ministro ha persistido en su idea de la centralidad y liderazgo de Tailandia entre los países de la llamada Cuenca del Mekong, sobre todo cuando se trata de las relaciones con el entorno regional más amplio donde necesariamente están China, Japón, Corea del Sur, Taiwán, y aun Estados Unidos.

Pero fue la cumbre de los líderes de APEC, celebrada en Bangkok en octubre de 2003, el escenario más propicio para el despliegue y lucimiento de sus capacidades diplomáticas, logísticas, de inteligencia y seguridad ante altos dignatarios mundiales, particularmente George Bush, el líder de la hiperpotencia mundial, en plena cruzada antiterrorista. La carta de acreditación de Thaksin no podía haber sido mejor: la entrega a Estados Unidos del terrorista más buscado del sureste asiático, de origen indonesio, Hambali, supuestamente ligado a los atentados de Bali y Yakarta, vinculado también a los ataques del 11 de septiembre (Ibarra, 2004: 268-274). Hambali fue apresado sólo unas semanas antes de la Cumbre en Tailandia, un país supuestamente "libre de terrorismo" según el propio Thaksin. Resulta evidente que tal muestra de eficacia y solidaridad con la cruzada antiterrorista mundial facilitó el inicio de las negociaciones en pro de un Tratado de Libre Comercio con Estados Unidos y la consecución del título de "El mayor aliado no nato de Estados Unidos en Asia". El colofón de todo esto también estuvo a la altura: el inédito envío de un contingente de soldados, técnicos y médicos tailandeses a Irak, como parte de la ya mencionada cruzada mundial contra el terrorismo. 
Si bien para muchos analistas y funcionarios de alto nivel los resultados de la Cumbre de APEC fueron magros, no lo fueron tanto para el primer ministro tailandés: aprovechó la coyuntura del evento para aprobar una controvertida ley antiterrorista y promovió activamente la "Thaksinomía", concepto que originalmente utilizó la prensa para referirse a la política económica del TRT, pero que a principios de 2002 terminó siendo cordialmente adoptado por el propio Thaksin, académicos, partidarios y amigos, incluso gobernantes como la presidenta (y economista) Gloria Arroyo, de Filipinas, quien llegó a utilizarlo (Phongpaichit y Baker, 2009: 99 y 100). Al respecto, y tal como ya se ha señalado en el presente trabajo, el concepto "Thaksinomía”, que el propio FMI ha definido como un nuevo modelo de desarrollo asiático y lo ha promovido como una vía eficaz para resolver las crisis económicas, para lo cual el caso de Tailandia sería ejemplar (Phongpaichit y Baker, 2009: 99), representa efectivamente un fuerte viraje del modelo neoliberal para la resolución de las crisis económicas que tradicionalmente el FMI ha venido introduciendo para tales efectos, bajo la receta de que la dinámica del crecimiento económico se regula, de manera natural, por las leyes del mercado. El Estado sólo debe coadyuvar a través de normas e instituciones para que el mercado funcione bien y libremente; por el contrario, el sesgo del "modelo thaksinómico" es hacia el desarrollismo, en el cual el Estado debe ejercer un rol positivo y activo, protegiendo y promoviendo el desarrollo económico, particularmente aquellos sectores menos dinámicos, para superar las asimetrías y desventajas que tiene el hecho de competir con economías más avanzadas. No obstante, la protección del mercado interno no debe inhibir el énfasis en la promoción de las exportaciones. Se trata de una economía nacional con fuertes implicaciones globales, de transitar al desarrollo por una doble vía o estructura dual, como les gusta definirse a los economistas thaksinianos.

En definitiva, el reconocimiento del FMI de que la experiencia tailandesa en la recuperación de la economía y superación de la crisis debe constituirse en una experiencia ejemplar para la región y que la "Thaksinomía" ha ganado credibilidad internacional, terminaron por convencer a los inversionistas extranjeros de que de nueva cuenta Tailandia era un buen lugar para hacer dinero; se constituyó en un éxito político-económico indiscutible de Thaksin, sustentado firmemente en indicadores económicos irrefutables: en 2004 la economía estaba creciendo entre 6 y $7 \%$, la tasa de crecimiento más alta desde 1997, año del estallido de la crisis; el índice de cotización de la Bolsa de Valores llegó a los 794 puntos frente a los 268 que existían en 2001, cuando 
el primer ministro inició su encargo; es decir, prácticamente triplicó su capacidad operativa (Phongpaichit y Baker, 2009: 226). Ya se ha mencionado también el beneplácito del FMI por el cumplimiento anticipado de Tailandia de sus compromisos financieros internacionales. Por otro lado, también hay que destacar que por lo menos desde 1932, es decir, los últimos 70 años de historia tailandesa, ningún líder político ha llegado a dominar el escenario público de la manera como la ha hecho Thaksin Shinawatra. Del mismo modo, ha quedado en evidencia que la administración de Thaksin ha sido una de las más activas en la historia de Tailandia en materia de política exterior, desde donde ha pugnado por llevar la batuta del liderazgo regional. Por último, y por si acaso faltara algo, en las elecciones generales de febrero de 2005, convocada justamente para la renovación de su mandato, obtuvo un triunfo apabullante. En verdad nunca nadie antes de Thaksin ha acumulado y ejercido tanto poder político por la vía democrática; sin embargo, no todo resultó exitoso.

\section{Las elecciones de 2005: el principio del fin}

Pareciera contradictorio sostener que un triunfo electoral contundente de un candidato signifique, al mismo tiempo, el inicio del fin de su carrera política gubernamental, pero así sucedió con Thaksin Shinawatra. Como sabemos, Thaksin accedió al poder tras ganar las elecciones generales de febrero de 2001 con $48 \%$ de los votos y 248 asientos parlamentarios. Fue reelecto como primer ministro en las elecciones generales de febrero de 2005 con $61 \%$ de los votos y 377 de los 500 asientos en el Parlamento, equivalente a $75.4 \%$ del control de las fuerzas parlamentarias, con lo cual se ha convertido en el único primer ministro que no sólo cumplió, sino que renovó su mandato constitucional en la historia política del país con apabullantes resultados.

Todavía más, las condiciones en que logró este contundente triunfo electoral multiplicaron su impacto y significado: las elecciones se realizaron en momentos en que Thaksin confrontaba los efectos negativos de sus reformas político-sociales; por ejemplo, contiende con los abusos policiales en su guerra contra el narcotráfico y la corrupción; es objeto de críticas por parte de los defensores de los derechos humanos como consecuencia de aquellos excesos; debe frenar la insurgencia islámica en las provincias del sur del país; debe contrarrestar los efectos del tsunami y de la fiebre aviar, que han azotado al país; debe hacer frente a las crecientes críticas de académicos y medios de comunicación en relación con su personal estilo de gobernar; debe confron- 
tar el afloramiento de algunos escándalos derivados de esa corrupta relación entre política y negocios que realizan sus familiares y, sobre todo, contender con la presencia de algunos signos de desaceleración económica que eran ya preocupantes.

Sorprende mucho, entonces, que pese al cúmulo de factores de oposición y desgaste político, se obtuvieran tan óptimos resultados electorales. ¿Cómo explicamos tal fenómeno? Indiscutiblemente que uno de los factores explicativos reside en la extraordinaria destreza política y capacidad organizacional de este "animal político" en que se ha convertido el primer ministro para sortear y negociar las dificultades y obstáculos político-electorales. Otra variable explicativa descansa, sin duda, en la gran centralización y control de las instancias político-administrativas regionales y estatales que garantizaron, tanto la gobernabilidad del país como la mantención de un control, acorde con los intereses del Gobierno. Otro factor, imprescindible y eficaz, fue el empleo de una sofisticada pero práctica, ingeniería electoral que no sólo utilizó una amplia red partidista y clientelar, sino que, llegado el momento, incurrió pragmáticamente en prácticas electorales deshonestas y fraudulentas, con el sólo afán de conseguir sus objetivos. En este terreno, el TRT, convertido en el principal partido político tailandés de alcance verdaderamente nacional, cumplió un papel insustituible. También la cooptación de movimientos sociales y partidos políticos regionales y locales ejerció su rol. Pero, no caben dudas, el liderazgo, la certeza de su poder, la fuerza de su carácter, su acentuado protagonismo, su falta de escrúpulos, la urgencia de resultados concretos, su olfato político y acentuado pragmatismo, etc., plasmados todos en su peculiar forma de gobernar, cuyo objetivo y prioridad fundamental no es otra que la populista y hasta casi demagógica consigna de: responder a las necesidades del pueblo, tuvieron mucho que ver en su aplastante triunfo electoral.

Respecto de lo anterior, no podemos olvidar el impacto popular extremadamente favorable que tuvo su "Agenda Nacional", promulgada en junio de 2000 que, entre otras ofertas se comprometía con una reestructuración económica y la formación de un mercado de capitales que no sólo financiara la recuperación de los agricultores y garantizara el mejoramiento de los ingresos de los pequeños comerciantes, sino que abatiera el desempleo, mejorara los servicios de salud y elevara los niveles educativos. Por esta vía, que muchos denominaron capitalismo popular, se impulsó la moratoria a las deudas rurales, la conformación de un fondo revolvente de un millón de baht por cada aldea tailandesa; se implementaron programas de subvenciones y créditos 
accesibles para los pequeños negocios y se estableció el precio máximo de 30 baht por cada visita médica, etcétera (Phongpaichit y Baker, 2009: 81 y 82), medidas todas que tuvieron una amplia y entusiasta acogida por parte de las masas rurales y urbanas de toda Tailandia, pero muy particularmente por la transferencia de millones de baht para revitalizar la producción, negocios y atención social de dichos sectores.

Regresando a lo que podríamos llamar el efecto demostración de las elecciones de 2005, diríamos que representaron el culmen del poder, no sólo parlamentario, de Thaksin Shinawatra. En los hechos, lo habilitaron para ejercer plenamente el poder, sin contrapeso alguno, al punto de que ha hecho públicas sus aspiraciones de permanecer en el gobierno por un largo tiempo, quizás 20 ó 24 años, emulando la regla de oro de "Un hombre, un partido" cultivada por Lee Kwan Yew en Singapur o Mahatir en Malasia. Y, por si faltara la cereza en su pastel, Thaksin no sólo presume, sino que desafía, que tiene detrás de sí casi 20 millones de votos, mismos que respaldan sus acciones y defienden sus decisiones. Si estas fanfarronerías asustaron a algunos, preocuparon a muchos más. Así, los detractores de Thaksin, aunque en franca minoría, empiezan a organizarse y a expresarse no sólo como un acto básico de sobrevivencia política, sino de resistencia a un ejercicio populista y autoritario de gobierno.

En efecto, a partir de las elecciones de 2005 empiezan seria y orgánicamente los intentos por contener a Thaksin. No es que desde antes no haya existido oposición a su gobierno. Ha existido siempre. Pero ahora es más vital, imperativa e impostergable, tanto para aquellos que han perdido bienes y privilegios, han visto disminuidas sus influencias, se sienten amenazados individual e institucionalmente, como aquellos que políticamente no están de acuerdo con los esquemas populistas de Thaksin. En general, su lógica es, cuando la democracia falla para conseguir la alternancia, es lícita la búsqueda de otros caminos. De allí lo paradójico del destino político de Thaksin: en su éxito electoral está, en gran parte, el fracaso de su futuro político. Pero todavía no es el momento de la debacle, aunque el proceso ya está en marcha.

La oposición a Thaksin es todo un espectro. Distinguiremos los principales. En primer lugar está el grupo de poder o estamento tradicional que se supone vinculado al Palacio Real y al Consejo de Estado, que es casi lo mismo. Conformados por miembros de la vieja guardia militar, altos funcionarios, burócratas y aristócratas reales, todos los cuales se escudan y/o utilizan al rey y su círculo familiar, la institución más preciada y respetada en todo 
tiempo y lugar en Tailandia para validar y potenciar sus demandas. Bajo esta fachada, este grupo de poder construye y difunde el discurso de que Thaksin es un político corrupto, inclinado a los negocios, cuya ambición, desmesura y exhibición de poder no sólo invade los espacios y estatus del rey, sino que también coloca en serio riesgo a las instituciones nacionales (léase monarquía y Consejo de Estado, los dos enclaves del poder tradicional), comprometiendo el futuro de Tailandia. Bajo esta lógica se acusa al primer ministro de "faltarle al respeto al rey Bhumibol, la persona más venerada en toda Tailandia", como ya se ha dicho, lo que lo hace susceptible, por tanto, de la aplicación de la ley de "lesa majestad", a través de la cual, como sabemos, se prohíbe cualquier tipo de crítica al rey, la reina, heredero al trono y el regente, so pena de sufrir encarcelamiento por un máximo de 15 años, constituyéndose hoy por hoy en una de las leyes más severas en todo el mundo. En la actualidad hay cientos de presos y otros tantos en proceso por este motivo (Jory, 2012). Como sea, lo importante de destacar aquí por parte de este grupo de oposición es su intento por vincularse a la Casa Real y a buena parte del Consejo de Estado $\mathrm{y}$, sobre todo, por la utilización de la figura real para fundamentar sus aspiraciones políticas. $\mathrm{Al}$ respecto, sobre estas bases y/o antecedentes, algunos críticos, tanto internos como externos al régimen monárquico tailandés, han desarrollado la hipótesis de que el rey Bhumibol no ha sido tan ajeno, indiferente y neutral a dicho movimiento, como en su retórica principista y "constitucionalista" lo presume.

Otro grupo es el de los desencantados o desilusionados políticos. A finales de los noventa Thaksin se presentaba como un reformista social, un agente del cambio, un defensor del capital doméstico, un empresario digno de confianza y un nacionalista a toda prueba, que convocaba a muchos académicos y seguidores. Pero el ejercicio y la estancia en el poder cambiaron muchas cosas y prioridades, particularmente su autoritarismo e inclinaciones al populismo, por lo que muchos de sus seguidores lo abandonaron y, algunos de ellos, se transformaron en sus acérrimos críticos. Uno de ellos, Anek Laothamatas, prestigiado cientista político tailandés, inspirado en el concepto de la "tiranía de las mayorías" de Tocqueville, lo califica de un gobernante que ejerce un "populismo irresponsable" (Phongpaichit y Baker, 2009: 240). Otro desencantado político resultó ser Surathian Chakratharanon, quien fue director general en el conglomerado empresarial Shinawatra por más de 10 años, un entusiasta, creyente e incondicional seguidor de Thaksin, en particular porque "ha sabido conquistar el corazón de las mayorías nacionales" para cambiar 
al país; sin embargo, con el tiempo ha sido tal la acumulación de poder y su ejercicio tan extremo, que Thaksin ha ido más allá de la acción propia de un verdadero estadista, para transitar hacia los peligrosos umbrales de un "terrible dictador". El riesgo es demasiado: en vez de seguridad, provoca temor. La misma desilusión invadió al reformador social Prawase Wasi, quien había calificado la llegada de Thaksin Shinawatra a la política tailandesa como una esperanzadora "bocanada de aire fresco". Igual cosa sucedió con el líder laboral Somsak Kosaisuk, quien acercó los sindicatos a Thaksin como una importante base de operación política, pero luego su "desenfrenado capitalismo" y "neoliberalismo globalizador" terminaron por alejarlo. Todos los desencantados o desilusionados de Thaksin, de quienes hemos mencionado algunos, no sólo lo abandonaron sino que lo condenaron por su creciente autoritarismo, su cruel y despiadado uso de la violencia en su guerra contra las drogas y corrupción, y la también constante utilización del poder del Estado para aumentar las ganancias de "Shin Corporation", el gran conglomerado empresarial de la familia Shinawatra (Phongpaichit y Baker, 2009: 227 y 228). En suma, todos ellos ya no ven a Thaksin como un factor de estabilidad y progreso, sino como un peligro para la democracia.

Por otro lado, su tinte autoritario y su intolerancia a la crítica lo hicieron entrar en colisión con dos grupos muy importantes en el campo de la generación y difusión de conocimientos e ideas, cuestión muy importante para la imagen y popularidad de un gobierno; me refiero a sectores académicos y medios de comunicación, quienes en los últimos tiempos no estuvieron de su lado. En efecto, tal como sucedió con otros sectores, la irrupción de Thaksin en la política, en la coyuntura 1998-2000, despertó el interés de muchos académicos e intelectuales que le dieron la bienvenida, especialmente por sus promesas de cambio. Pero, conforme avanzó su régimen y puso en práctica su estilo de gobernar, surgieron las críticas, algo muy propio y natural de la actividad académica e intelectual, particularmente en asuntos como el funcionamiento de la democracia y la formulación de la política exterior.

La reacción de Thaksin frente a sus críticos fue muy fuerte e intolerante, no sólo los tildó de obsoletos e ignorantes que "sólo hablan de los problemas, pero no de las soluciones”, sino que amenazó con una purga en las universidades para depurar los estamentos académicos y retener solamente a aquellos investigadores nacionalistas y comprometidos con el avance del país. A manera de ejemplo, basta recordar la inusual vehemencia con la que el primer ministro replicó a Thirayuth Boonmi, un ex líder estudiantil de 1973 
y ahora un prominente luchador por la democracia en Tailandia, quien había calificado a su gobierno como autoritario. Thaksin no sólo lo descalificó como una persona que quiere vivir como héroe sin haber hecho nada útil para la sociedad, sino que le reclama el vivir del presupuesto público, sin merecerlo. Igual cosa sucedió con el antiguo ex primer ministro Anand Payarachun, a quien Thaskin mandó literalmente a callar, después de que éste se atreviera a regañarlo públicamente, aunque de manera afable, por su manera de gobernar. Por su parte, el connotado economista Ammar Siamwalla, quien había criticado el alto costo económico del desmesurado populismo del gobierno, hizo un voto de "silencio público", después de que Thaksin le llamara ignorante. Los casos podrían seguir.

La reacción del primer ministro frente a las críticas externadas a través de los medios fueron mucho más agresivas y descalificadoras, cuestionando siempre las credenciales y los motivos de los periodistas que se atrevían a criticarlo. Al respecto, su juicio es categórico: "Las personas en otros países —refiriéndose naturalmente a los periodistas - colocan el interés nacional por encima de cualquier cosa, pero aquí, la gente critica solamente porque necesita verse cool", y prosigue: "Ustedes, la gente de los medios deben creerme. Hoy día, servir al país es más importante que estar enviando diariamente sus despachos noticiosos a sus editores. Piensen, antes de realizar cualquier tarea periodística, que esa acción puede dañar al país" (Phongpaichit y Baker, 2009: 157). El tema aquí es que para Thaksin cualquier crítica personal y a su gobierno significa automáticamente un ataque a la nación toda. Es más, toda discusión y oposición a su liderazgo político era, por definición, ilegítima y antinacional. Las controversias llegaron a tal extremo que el propio rey, en su discurso de celebración de su cumpleaños en diciembre de 2003, con Thaksin frente a él, dijo: "yo sé que al primer ministro no le gusta ser criticado, porque la crítica nos hace enojar, pero [...]" (Phongpaichit y Baker, 2009: 228). En definitiva, la intolerancia de Thaksin frente a la crítica polarizó los medios, al igual que otros sectores.

Comentario aparte merece Sondhi Limthongkul, primero un ferviente apoyador de Thaksin, y después uno de sus más tenaces detractores y enemigo político declarado. Bien podría calificarse como una historia de amor y odio, con el consabido ingrediente de la pasión, en dosis alta. En efecto, en la década de los noventa Sondhi era ya el director de un importante grupo dedicado a las actividades editoriales y comunicacionales, editor de Asia Times, propietario de periódicos y medios televisivos y accesos satelitales. Su contacto con Thaksin 
fue prometedor y, desde ese momento, se transformó en uno de los más entusiastas apoyadores de su proyecto político, para lo cual aprovechó algunas de sus plataformas comunicacionales. Inesperadamente la crisis de 1997 lo llevó a la bancarrota, frente a lo cual Thaksin, encumbrado ya en el poder, le tendió la mano y lo sacó de esa crítica situación a través de condonación de deudas y otorgamiento de concesiones, entre las cuales habría que mencionar el posicionamiento en un programa televisivo semanal de amplia audiencia: "Thailand Weekly", desde el cual obviamente promovió la figura de Thaksin.

Todo iba bien hasta que, también inesperadamente, en agosto de 2005 Sondhi cambió de opinión y se volcó contra Thaksin. Se especula que la ruptura se debió a un conflicto de intereses. Como haya sido, el hecho es que a partir de ese momento Sondhi empezó a constituirse en una de las cabezas de la cruzada anti-Thaksin, empleando todos los medios comunicativos y organizacionales a su alcance para sacarlo del poder. Por su parte, Thaksin y sus seguidores no sólo acusan a Sondhi de vil desertor, sino de traidor a las causas populares. Acto seguido Sondhi se autoproclama como defensor de la clase media amenazada por el vuelco político del primer ministro hacia el populismo, acusándolo, por supuesto, de corrupción y abuso de poder, difundiendo denuncias de tales prácticas y advirtiendo del peligro del autoritarismo. En los hechos, Sondhi se transforma en el gran vocero de la oposición y uno de los líderes del movimiento anti-Thaksin. Su rol no es menor, se trata de un empresario de los medios, poseedor de periódicos, revistas, estaciones de radio y televisión por cable, muy popular en el website y un activista de cuidado.

Lo mismo ocurrió con sus críticos y detractores respecto de las políticas aplicadas a la insurgencia musulmana y malaya en las provincias del sur de Tailandia, que datan de al menos dos siglos. Tales políticas, con lógica predominantemente militar y abiertamente represivas, no sólo le atrajeron severas críticas internas, sino también externas, particularmente de Malasia. A finales de 2004 en tres provincias de sur del país han ocurrido unos 1,843 incidentes y las víctimas fatales han llegado a 680 (Phongpaichit y Baker, 2009: 242).

Pero el verdadero talón de Aquiles de Thaksin fueron las acusaciones de usar y manejar el país como un negocio personal y familiar. Al respecto, sólo un par de cifras bastan para documentar esta crítica: primero, al asumir el cargo de primer ministro en 2001 su fortuna personal se estimaba en alrededor de 2,000 millones de dólares; en 2004, el año cumbre de su administración, su patrimonio personal llegaba a los 5,000 millones de dólares (Phongpaichit y Baker, 2009: 226); segundo, las ganancias netas de Shin Corporation casi 
se han cuadruplicado entre 2001 y 2004; es decir, de 2,600 a 9,600 millones de baht (Phongpaichit y Baker, 2009: 386). Algo impresionante. No es extraño, entonces, que el detonante que acentuó la crisis internas y precipitó la intervención militar, que muchos estaban ya demandando, se localizara en el ámbito económico financiero y se empezara a gestar a principios de 2006, el 23 de enero para ser más preciso, cuando la familia Shinawatra vendiera 49.61\% del Holdings Shin Corporation a Temasek, una empresa pública de Singapur, en 1,700 millones de dólares. La operación se realizó a través de prestanombres de una empresa gestora cuyo domicilio fiscal se encontraba en las Islas Vírgenes Británicas, conocido paraíso fiscal, no sólo con el objeto de eludir la prohibición de la venta de una empresa estratégica como ésta a otra empresa extranjera, tal como estaba establecido en las regulaciones constitucionales, sino también para eludir el pago de impuestos por dicha venta. Por si esto no bastara, también se hizo pública la evidencia y la subsecuente acusación de que Thaksin ayudó a su esposa Pojaman en la adquisición de unos terrenos fiscales por un valor muy por debajo de los precios del mercado: 16.6 millones de euros por cinco hectáreas en pleno centro de Bangkok. ${ }^{3}$ El escándalo estalló de inmediato, sobrevino una explosión de enojo público y molestia generalizada, y las diferencias entre Thaksin y sus opositores se tornaron irreconciliables y violentas.

A partir de allí, la campaña anti-Thaksin arreció, la oposición creció y la sociedad tailandesa se polarizó. Por un lado, una poderosa camarilla de oposición nucleada en torno a una orquestada defensa de la Casa Real, la anticorrupción y una supuesta defensa de la democracia; por otro, un amplio frente de apoyo popular, rural y urbano, construido a partir de las políticas populistas de Thaksin, quien también cuenta con el apoyo de una imagen positiva a nivel internacional por haber sacado al país de la crisis y haber transformado a Tailandia en un lugar atractivo para las inversiones y los negocios. La polarización se manifiesta también por la manipulación de los contrastes: por una parte, la utilización de la imagen de un Thaksin corrupto, cabeza de un gobierno inmoral y autoritario; por otra, la figura intachable del rey, con gran solvencia ética y alta calidad moral, garante de la estabilidad institucional, cuya experiencia y poder debe estar, incluso, por sobre la Constitución.

En el terreno de las actividades, imágenes e incluso desplantes de Thaksin, la oposición, con Sondhi a la cabeza y el apoyo de la PAD; es decir, la "Alianza

3. http/www.es.wikipedia.org_wiki_Gobierno_interino_de_tailandia_bajo_control_militar, pp. 20 y 21. 
del Pueblo para la Democracia”, organización política creada ex profeso, elaboraron todo un "prontuario" para "documentar" sus denuncias y solidificar sus acusaciones de que Thaksin es un peligro para Tailandia, y obviamente para el rey. Por ejemplo se denuncia que en celebración de su cumpleaños en su ciudad natal, Sankamphaeng, se montó un escenario y se desplegó un boato muy similar a las celebraciones reales, con lo cual estaría emulando al rey; luego, la utilización del Gran Palacio, concretamente el Templo de la Esmeralda de Buda, para la realización de una ceremonia cívico-religiosa-protocolaria, en abril de 2005, dio pie para la acusación de que Thaksin estaba invadiendo un espacio y funciones que sólo son prerrogativas de la Casa Real. Aún más, la oposición desentierra y difunde un viejo y controvertido incidente que responsabiliza a Thaksin y otros cinco miembros del TRT de planear, en Finlandia en 1999, el derrocamiento de la monarquía y el establecimiento de la República de Tailandia, nombrando a Thaksin como su primer presidente, cargo que por supuesto fue calificado por el mismo como "una completa fantasía" (Phongpaichit y Baker, 2009: 269).

Así, por más que Thaksin insista en que no ha hecho uso de su posición como primer ministro para favorecer los negocios del imperio Shinawatra, cosa que por lo demás muchos tailandeses ven como natural y propia de los privilegios de su liderazgo, no ha podido contrarrestar los ataques y ofensivas de la oposición, que han ido creciendo progresivamente. Desde la primera conferencia llamada "Los enemigos de Thaksin", septiembre de 2004, que tímidamente demandaba la renuncia del primer ministro, hasta la convocatoria a la toma de la Casa de Gobierno (enero 2006) y la formación de la PAD, las movilizaciones se tornaron en abiertamente conspirativas y radicales. Las consignas de la oposición así lo reflejan: "Salvemos a la nación", "Nosotros amamos al Rey", "Nosotros pelearemos por el Rey" "Thaksin por favor déjanos”, “Thaksin fuera”, “¿Dónde están los militares?”, etcétera (Phongpaichit y Baker, 2009: 268-270).

Ante tales ofensivas y la imposibilidad absoluta de la conciliación, Thaksin se "vuelca" hacia el pueblo, en busca de su legitimización. Para dirimir las controversias políticas apela, entonces, al recurso fundamental de la democracia: las elecciones. Consecuentemente, el día 24 de febrero de 2006 decretó la disolución del Parlamento y convocó a elecciones generales, bajo la consigna de "defender la democracia parlamentaria frente a las amenazas externas al sistema: "Firme con la Democracia", "Predominio de la ley y la Constitución", 
"Adelante con las reformas políticas en Tailandia", etcétera (Phongpaichit y Baker, 2009: 277) serán sus consignas principales.

Las elecciones se realizaron el 2 de abril de 2006; ese día votaron unos 30 millones de tailandeses, un poco menos que los 31 millones de tailandeses que lo habían hecho en las elecciones de 2005; como partido el TRT obtuvo 56\%, en comparación con $61 \%$ de la votación obtenida en 2005 . Por supuesto que hay un desgaste político respecto de las elecciones de 2005, pero aún Thaksin conserva una sólida mayoría parlamentaria y unos 16 millones de votos respaldan su gestión (Phongpaichit y Baker, 2009: 274). Independientemente de algunas contingencias postelectorales, una cosa ha quedado absolutamente clara para la oposición tailandesa: por la vía de la democracia electoral es imposible derrotar a Thaksin. Habrá que buscar otro camino.

En un contexto de extrema polarización política, el movimiento antiThaksin apeló al poder moral, pero sobre todo al supuesto poder constitucional del rey para deponer a Thaksin. Según esta tesis el rey está por sobre la Constitución en tanto jefe de Estado, y en virtud del artículo 7 está facultado para nombrar al primer ministro en caso de crisis o emergencia nacional. Y tal sería el caso. No obstante el despliegue y movilización de las fuerzas de oposición, la respuesta del rey fue clara y categórica:

El artículo 7 no faculta al rey para tomar una decisión unilateral. Habla acerca de la monarquía constitucional, pero no le otorga al rey el poder para hacer lo que él quiera. Si el rey hiciera eso, estaría transgrediendo su deber. Yo nunca he traspasado este deber. Hacerlo, sería antidemocrático (Phongpaichit y Baker, 2009: 274).

Entonces, frente a la inviabilidad de este último recurso supuestamente legal, el expediente para la vía y la acción extrema del golpismo está prácticamente listo: la inestabilidad, ingobernabilidad y extrema polarización política reclaman la mano militar como la única fuerza capaz de poner orden y salvar al país del caos. La lógica golpista terminará por imponerse.

\section{Epílogo. Democracia interrumpida: el pesado lastre de la tradición golpista}

El golpe de Estado (GdeE) del 19 de septiembre de 2006 por parte de las Fuerzas Armadas en contra del Gobierno del primer ministro Thaksin Shi- 
nawatra en Tailandia, no sólo nos recordó dramáticamente la larga tradición golpista en dicho país, sino sobre todo la abrupta interrupción del proceso de construcción y consolidación de la democracia, en el transcurso de la última década del siglo pasado y principios del presente, proceso que para algunos era irreversible. En efecto, el GdeE, que habría que identificar como unos de los principales obstáculos en la ruta democrática de Tailandia, puso fin a más de 15 años de gobiernos civiles, con sus respectivas y a veces conflictivas sucesiones, a través de elecciones "formalmente libres y democráticas", que dieron origen a otros tantos gobiernos que supieron y pudieron resolver crisis (1997-98), contender con la gobernabilidad, crear institucionalidad democrática y confrontar los avatares de la democracia tailandesa con relativa eficiencia (Toledo, 2012: 44 y 45). Algo inédito en la historia política moderna y contemporánea de este país.

No obstante, bastaron el conjunto de circunstancias reseñadas anteriormente, todas muy propias de la política tailandesa, para que el peso de la tradición y tentación golpista se desencadenara. Al respecto, habría que recordar que después del GdeE de 1991, pero sobre todo después de las "Jornadas de mayo" en contra de la cúpula militar y de las elecciones de septiembre de 1992, "las más justas y limpias en Tailandia desde 1932", no sólo fraguaron el proceso de remoción de los militares del poder político, sino que propiciaron el establecimiento de la democracia, con predominio y control de la sociedad civil por más de una década y media. De ahí, hasta septiembre de 2006, el proceso democrático no se había interrumpido.

La presencia de tanques, vehículos blindados y soldados en los alrededores del Parlamento, la Casa de Gobierno, el Ministerio de Defensa, en las calles y puentes de Bangkok, así como la suspensión de la Constitución, la disolución del Parlamento, del gabinete ministerial y la declaración de la ley marcial en todo el país por parte de una Junta Militar en septiembre de 2006, nos recordó también, abrupta y dramáticamente, el peso de otra estadística histórica relevante: en Tailandia, desde 1932, fecha en que se constituyó en un Estado monárquico, constitucional y democrático, hasta septiembre de 2006, se han sucedido 18 golpes de Estado que han dado origen a otros tantos gobiernos de facto. En el mismo lapso, de un poco más de 75 años, Tailandia ha tenido 17 Constituciones, incluyendo la última de 2007, que legitimó el derrocamiento de Thaksin Shinawatra.

Así, golpe tras golpe, Constitución tras Constitución, partidos políticos, instituciones y prácticas democráticas han sido establecidas, abolidas, prohi- 
bidas, refundadas, debilitadas, etc., según las conveniencias de los gobiernos en turno, generando por lo menos un contexto de gran dinamismo, complejidad, inestabilidad y problemas de gobernabilidad en la política tailandesa. $\mathrm{Al}$ respecto, la estadística sigue siendo elocuente y contundente: en 79 años se han sucedido unos 40 primeros ministros, que han formado 60 gobiernos al frente de Tailandia. Consecuentemente, la sociedad tailandesa, como un todo, se ha visto permanentemente confrontada por un clima de tensiones sociales derivadas de la inestabilidad política, constituida ya en una suerte de atavismo sociopolítico que impide su desarrollo y modernización.

Como ha quedado claro, los grandes damnificados por el golpe de septiembre de 2006 fueron, sin duda alguna, la democracia y el primer ministro Thaksin Shinawatra, quien, al asumir dicho cargo en febrero de 2001, se había autoproclamado como el más vehemente y tenaz defensor de la democracia, particularmente frente a todas aquellas prácticas, "formas e influencias oscuras" que la obstruyen, sin precisar si entre ellas se encontraba la perversa Manus militaris como factor de desestabilización democrática, aunque poco tardó en comprobarlo. También quedó perfectamente claro que los grandes beneficiarios del golpe fueron una buena parte de la casta militar y el llamado estamento de poder tradicional.

A la hora de los hechos, los golpistas procedieron con "el libro de texto sobre golpes de Estado" en la mano, aprovechando la coyuntura extremadamente favorable de que Thaksin había emprendido una gira por el extranjero, cuya agenda diplomática culminaba en Nueva York para participar en la sesión de la Asamblea General de la Naciones Unidas, desde donde dirigiría un mensaje al mundo. Su ausencia del país resultó extremadamente propicia para desencadenar el GdeE. Y así se procedió, aunque a confesión explícita de algunos generales golpistas, el referido golpe se había venido preparando al menos con unos seis a ocho meses de anticipación (Phongpaichit y Baker, 2009: 283).

El 19 de septiembre de 2006, unidades militares del Real Ejército Tailandés tomaron Bangkok; la sede del Gobierno fue ocupada por el Ejército y rodeada de tanques de guerra, llevaron a cabo el GdeE que derrocó, en ausencia, al primer ministro Thaksin Shinawatra. No hubo resistencia por parte de otras unidades del Ejército, ni de otras fuerzas, resultando en un golpe incruento. La Junta Militar quedó encabezada por el general Sonthi Boonyaratklin, quien de inmediato abolió la Constitución, disolvió la Asamblea Nacional y la Corte Constitucional; es decir, disolvió los poderes Ejecutivo, Legislativo y Judicial; 
impuso la ley marcial, prohibió los partidos y las actividades políticas, estableciendo además la censura de prensa y el control de las comunicaciones. Es decir, lo clásico en todo GdeE y mucho más en Tailandia, con una ya tan larga y generosa experiencia sobre la materia.

Como era de suponer, los golpistas declararon su lealtad al rey Bhumibol Adulyadej y crearon el Consejo para la Reforma Democrática bajo la Monarquía Constitucional, nombre que adoptará la Junta Militar en adelante, una vez que asumió todos los poderes y que fue oficial y automáticamente reconocida por el rey. Al respecto, tremendamente reveladora y elocuente resultó una fotografía liberada un par de días después del golpe, donde se muestra a los generales Sonthi Boonyaratklin, quien dirigió y ejecutó el golpe, el general Ruangroj Mahasararon, supuestamente promovido por Thaksin como futuro comandante en jefe y, por supuesto, el general Prem Tinsulanonda, presidente del Consejo de Estado, arrodillados frente al rey y la reina, no sólo expresando lealtad suprema al monarca, sino también testimoniando, de alguna manera, el carácter de "misión cumplida" de la intervención militar en la arena política tailandesa (Phongpaichit y Baker, 2009: 284).

Por si hiciera falta, los argumentos que esgrimieron los golpistas para justificar su intervención fueron: "insultos a la monarquía", "grave crisis y deterioro del sistema político", como resultado de la "corrupción y abuso de poder" por parte del primer ministro, lo que ha conducido a una "inaudita división social", nunca antes vista en la historia de Tailandia.

En el ámbito internacional, área muy importante para la estrategia de desarrollo orientada a la exportación del llamado "modelo tailandés" y sobre el cual Tailandia ha venido construyendo un cierto liderazgo regional, la intervención militar fue vista con preocupación por vecinos y socios comerciales importantes. Así, Camboya, Estados Unidos, Japón, Nueva Zelandia, entre otros, lamentan la interrupción del camino democrático y abogan por la pronta restitución del régimen democrático. ${ }^{4}$

En definitiva, y como se ha dicho, el golpe de Estado no sólo interrumpió el proceso democratizador, sino que dejó a Thaksin en el inmediato y total exilio, primero en Nueva York, luego en Londres, y finalmente en Dubai, sin posibilidad alguna de luchar por la defensa de su poder y restauración de su gobierno. Desde allí instó a la convocatoria de elecciones generales cuanto antes: "esperamos que el nuevo régimen prepare sin demora nuevas elecciones

4. http/www.es.wikipedia.org_wiki_Gobierno_interino_de_tailandia_bajo_control_militar, pp. 62-67. 
generales y que preserve los principios de la democracia". ${ }^{5}$ Sin embargo, ya no es el primer ministro y no está frente al gobierno tailandés para controlar el curso de la historia y la política nacional tailandesa.

\section{Referencias bibliográficas}

Ibarra, Guadalupe (2002), “Tailandia”, Anuario Asia Pacífico 2002, México: El Colegio de México-Centro de estudios de Asia y África.

-_ (2004), "Tailandia”, Anuario Asia Pacífico 2004, México: El Colegio de México-Centro de estudios de Asia y África.

Jory, Patrick (2012), "The crisis of the Thai monarchy", East Asia Forum, núm. 2, febrero, disponible en: http://www.eastasiaforum.org/2012/02/02/ the-crisis-of-the-thai-monarchy/

Phongpaichit, Pasuk, y Baker, Chris (2009), Thaksin, $2^{\text {a }}$ edición aumentada, Bangkok: O. S. Printing House.

Toledo Beltrán, José Daniel (2011), Tailandia de principios del siglo Xxı: El peso de la historia, presentado en el seminario auspiciado por Universidad de Colima, El Colegio de México y la Embajada Real del Reino de Tailandia en México, XI Seminario Internacional de Investigación sobre la Cuenca del Pacífico, Colima, México, del 22 al 23 de septiembre de 2011.

- - (2012), "Tailandia: De cara al siglo xxI”, en Ramírez Bonilla, Juan José, y González García, Juan (coords.), Tailandia y México. Retrospectiva de una relación intermitente, México: Embajada Real de Tailandia/Miguel Ángel Porrúa.

5. http/www.es.wikipedia.org_wiki_Gobierno_interino_de_tailandia_bajo_control_militar, p. 34. 